or England and Wales cannot be generalised to other parts of the world such as India. India is the second most populous country in the world and approximately $80 \%$ of the population are farmers and poorly educated. Unfortunately, even after more than 50 years of Indian independence, farmers, who are perceived to be the backbone of the nation, are neglected in many ways. Because of this, last year, in the northern part of Karnataka State (south India), many districts like Bidar, Gulbarga, Raichur and Bijapur experienced not less than 100 suicides of farmers within three months (March-May) ("Another farmer commits suicide", "Money-lenders blamed for farmers' suicide", "Bellary farmers end life over crop loss", Deccan Herald, 15 March, 3 April and 11 May 1998). Today, the suicide rate in farmers in India is still not known. Malmberg et al discussed the lacunae in understanding of farmers' suicide problems and this is an area for more research.

In contrast to the Hawton et al study, farmers' suicides in India may be associated with different problems such as harassment by money-lenders, inability to repay debts following crop loss, inability to get medical treatment for the family, etc.

In developing countries like India globalisation and industrialisation are prominent, with multi-national companies competing in the industrial and agricultural sectors. This adds, directly or indirectly, to numerous problems such as supply of low-quality seeds to farmers, sales of sub-standard alcoholic drinks, sub-standard pesticide production and frequent power cuts and irregular power supplies. The lack of positive and cooperative support from banks and too many restrictions make problems worse. Unless there is a supportive government policy for safeguarding farmers during inclement weather or market fluctuations, and until banking systems are put in order, the plight of farmers will remain the same.

Furthermore, suicide in farmers could be controlled by effective and efficient community care, which has been a cornerstone of policy for mental health services for the past half-century (Tyrer, 1998). Policy concerns and research efforts should focus on reducing suicide in farmers.

Hawton, K., Fage, J, Simkin, S., *t of (19\%) Methods used for suicide by farmers in England and Wales. The contribution of availability and its relevance to prevention. British joumal of Psychiotry, I73, 320 324.
Malmbers, A., Simkin, S. A Hawton, R. (I999) Suicide in farmers. British fournol of Psychiatry. I75, $103-105$

Trres, P. (ISe3) Whither community care? British journal of Psychiotry 173, 359-360.

M. Sundar Department of Community Medicine, KIMS, VV Puram, KR Road, Bangalore, India

\section{Fever and acute brief psychosis in developing countries}

Sir: The study by Collins et al (1999) represents a significant advance in addressing the aetiological factors underlying acute brief psychosis, a common problem in developing countries but with very little systematic data available. Although the authors have only considered the aetiological significance of viral infections such as influenza and herpes simplex, the real difference between developing and developed countries lies in the prevalence of bacterial and protozoal infections. It appears that the authors have overlooked the significance of these commonly occurring infections and the drugs used to treat these in the aetiology of acute brief psychosis.

Two common causes of fever in developing countries are malaria and typhoid fever. These infections, as well as their treatments, may have direct aetiological implications for acute brief psychosis. Apart from the indirect effects of malaria and its complications on the activation of psychotic symptoms, cerebral malaria may have similar direct effect. Cerebral malaria is not uncommon in these settings. It has been reported in $20-40 \%$ of patients admitted with fever and altered consciousness (Durrani et al, 1997). Psychosis is also considered one of the side-effects of the most commonly employed treatment for malaria, chloroquine.

A toxic confusional state characterised by disorientation, delirium and restlessness, is characteristic of late-stage typhoid but, occasionally, these and other neuropsychiatric features may dominate the clinical picture from an early stage (Osuntoken et al, 1972; Breaky \& Kala, 1977). Moreover, it is well known that the quinolones, now the most effective and widely used group of antibiotics in typhoid, can cause psychotic symptoms such as hallucinations.

These points serve to highlight the interplay of various biological factors in the aetiology and perhaps in the manifestations of acute brief psychosis in developing countries. There is a dire need for similar studies on the subject in these settings, which may also help in a search for finding the aetiology of psychosis in general.

Drealsy K R. \& Kab, A. R. (IST) Typhoid catatonia responsive to ECT. British Medical fournd, ï, 357-359.

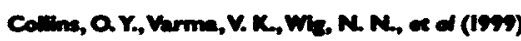

Fever and acute brief psychosis in urban and rural settings in north India. British foumd of Psychiotry 174. 520-524.

Durrani, A. B., Durranl, L U, Abbes, Nh, et of (IMH) Epidemiology of cerebral malaria and its mortality. journal of Aakiston Medical Association, 47, 213-215.

Onuntolen, B. O, Bedemod, Q, Ogursonl, K, ex ef (1972) Neuropsychiatric manifestations of typhoid fever in 959 patients. Avchives of Neurologx $27,7-13$.

S. Faroog, M. Y. Khemlin Psychiatry Department, Postgraduate Medical Institute, Lady Reading Hospital, Peshawar, Pakistan

People at risk of schizophrenia and other psychoses: comments on the Edinburgh High-Risk Study

Str: Hodges et al (1999) present a research design to study the process of transition to psychosis. Our purpose is to make some constructive comments on the paper and to describe an alternative research strategy which has similar aims.

Although the paper attracted criticism, mainly because of views about premature publication, we believe the study has merit. The problems of the study, however, relate more to design issues. The authors highlight the failure of the traditional high-risk strategy to realise its potential, and propose a partial solution. This failure is partly a result of the long latency to expression of risk in most (but not all) of these studies, and partly is due to the sole reliance on family history as a risk marker. The Edinburgh study appears at first glance to address the first weakness, yet this turns out to be a limited solution. The second weakness remains. The sample is defined as high-risk on genetic grounds only, a necessary consequence of restricting the sample to 'well' or pre-symptomatic individuals. This ultimately extends the latency of the expression of risk and hence the length of the follow-up period and limits the generalisability of the findings to psychosis or schizophrenia as a whole, since a small minority only of cases have this pattern of family history. The advantage is that the patients who develop psychosis will have been assessed from the asymptomatic 